\title{
Dependence of peptidoglycan metabolism on phospholipid synthesis during growth of Escherichia coli
}

\author{
Dmitrii G. Rodionov and Edward E. Ishiguro \\ Author for correspondence: Edward E. Ishiguro. Tel: +1 604721 7071. Fax: +1 6047218855. \\ e-mail: EISHUV@UVVM.UVIC.CA
}

Department of

Biochemistry and

Microbiology, University of

Victoria, PO Box 3055 ,

Victoria, British Columbia,

Canada V8W $3 P 6$

\begin{abstract}
The role of phospholipid synthesis in peptidoglycan metabolism during growth of Escherichia coli was determined. The inhibition of phospholipid synthesis, achieved by inhibiting fatty acid synthesis with cerulenin or by glycerol deprivation of gpsA mutant strains, resulted in the concomitant inhibition of peptidoglycan synthesis. These effects on peptidoglycan synthesis were relatively specific in that the treatments did not cause a general inhibition of macromolecular synthesis. Furthermore, the inhibition of phospholipid synthesis also resulted in the rapid development of penicillin tolerance. It was unlikely that penicillin tolerance in these cases were simply due to the inhibition of growth caused by cerulenin treatment or glycerol deprivation because treatments with more effective growth inhibitors, e.g. chloramphenicol or norfloxacin, did not confer penicillin tolerance. Penicillin tolerance was shown to be a direct consequence of the inhibition of phospholipid synthesis and not due to the possible accumulation of guanosine$3^{\prime}, 5^{\prime}$-bispyrophosphate (ppGpp), the starvation stress signal molecule known to be responsible for the development of penicillin tolerance in amino-aciddeprived bacteria. Therefore, peptidoglycan metabolism is coupled to phospholipid synthesis during growth of $E$. coli, and this may represent an important means to ensure the coordination of cell envelope synthesis in growing bacteria.
\end{abstract}

Keywords: penicillin tolerance, peptidoglycan, phospholipid, Escherichia coli, $\beta$-lactam antibiotics

\section{INTRODUCTION}

Peptidoglycan is the covalently closed bag-shaped macromolecular component of eubacterial cell walls. The synthesis of peptidoglycan is widely believed to require not only the peptidoglycan polymerase activities of the high-molecular-mass penicillin-binding proteins (PBPs) but also the activities of certain peptidoglycan hydrolases (for reviews, see Höltje \& Tuomanen, 1991; Höltje, 1995). Very little has been established with regard to the mechanism by which PBPs and peptidoglycan hydrolases participate in the synthesis of peptidoglycan. The peptidoglycan hydrolase activities also play a decisive role in the killing action of inhibitors of peptidoglycan synthesis

Abbreviations: DAP, diaminopimelic acid; PBP, penicillin-binding protein. such as the $\beta$-lactam antibiotics. Treatment of bacteria with such agents apparently uncouples the peptidoglycan hydrolase activities normally involved in the biosynthetic process, and their hydrolytic action on the existing peptidoglycan is responsible for the characteristic cell lysis which occurs.

Nongrowing bacteria are tolerant to the killing action of $\beta$-lactam antibiotics. In the case of amino-acid-deprived Escherichia coli, penicillin tolerance has been attributed to the phenomenon known as the stringent response (Kusser \& Ishiguro, 1985). Amino-acid-deprived E. coli cells rapidly accumulate the novel nucleotide guanosine $3^{\prime}, 5^{\prime}$ bispyrophosphate (ppGpp), which is believed to mediate the stringent response by globally inhibiting a diverse array of metabolic processes. Therefore, the stringent response probably represents a means of enhancing bacterial survival during periods of amino acid deprivation (for a review, see Cashel \& Rudd, 1987). The 
synthesis of ppGpp during the stringent response is catalysed by ppGpp synthetase $I$, a ribosome-associated enzyme encoded by the $\operatorname{rel} A$ gene, which is activated during amino acid deprivation. The stringent response can be eliminated (i.e. relaxed) by inhibiting the synthesis of ppGpp. This may be accomplished either by introducing a mutation in the $\operatorname{rel} A$ gene or by treating aminoacid-deprived $\mathrm{rel} \mathrm{A}^{+}$bacteria with certain ribosome inhibitors, e.g. chloramphenicol, which apparently interfere with the activation of RelA. Under certain conditions of nutritional stress, e.g. energy source starvation, a RelAindependent accumulation of ppGpp is observed. This process is catalysed by ppGpp synthetase II, which has been identified as the product of the spo $T$ gene (Hernandez \& Bremer, 1991; Xiao et al., 1991). Of direct relevance to this study is the observation that SpoT catalyses the accumulation of ppGpp when fatty acid synthesis is inhibited in E. coli (Seyfzadeh et al., 1993).

Sokawa et al. (1968) first demonstrated that phospholipid synthesis is inhibited during the stringent response. Heath et al. (1994) have subsequently proven that ppGpp directly mediates this process by showing that the overproduction of ppGpp in normal growing $E$. coli, achieved through the controlled overexpression of the cloned $r e l A$ gene, resulted in the inhibition of phospholipid synthesis. Furthermore, the observed inhibition of phospholipid synthesis was relieved by the overexpression of the $p l s B$ gene, which encodes $s n$-glycerol-3-phosphate acyltransferase, and this indicates that $\mathrm{PlsB}$ is the enzyme inhibited by ppGpp.

The synthesis of peptidoglycan (Ishiguro \& Ramey, 1976) and penicillin-induced lysis (Kusser \& Ishiguro, 1985) are also inhibited during the stringent response. The following observations indicate that phospholipid synthesis plays a pivotal role in regulating peptidoglycan metabolism and $\beta$-lactam-induced lysis in amino-acid-deprived cells. (i) The terminal stage of peptidoglycan synthesis, apparently corresponding to the activities of the PBPs, has been shown to be obligately dependent on phospholipid synthesis when the stringent response is relaxed in amino-acid-deprived bacteria ; i.e. the inhibition of relaxed phospholipid synthesis in amino-acid-deprived cells results in the concomitant inhibition of relaxed peptidoglycan synthesis (Ishiguro, 1983). (ii) Rodionov et al. (1995) have recently demonstrated that the lysis of relaxed amino-acid-deprived bacteria induced by treatment with $\beta$-lactam antibiotics is also dependent on phospholipid synthesis; their results suggest that both PBP and peptidoglycan hydrolase activities exhibit this dependence. (iii) The overproduction of ppGpp, resulting from the overexpression of the $\mathrm{rel} A$ gene in otherwise normally growing bacteria, causes the inhibition of both peptidoglycan and phospholipid synthesis and results in the development of penicillin tolerance (Rodionov \& Ishiguro, 1995). Furthermore, the overexpression of PlsB under these conditions eliminates the penicillin tolerance conferred by ppGpp accumulation. In summary, studies to date indicate that ppGpp accumulation during the stringent response directly inhibits $\mathrm{Pls} B$, and this, in turn, results in the coordinate inhibition of PBP and peptido- glycan hydrolase activities, and, consequently, in penicillin tolerance.

The objective of the present study was to determine whether the observations made on amino-acid-deprived E. coli could be extended to normal growing bacteria. We demonstrate here that peptidoglycan metabolism is indeed coupled to concomitant phospholipid synthesis during growth of E. coli.

\section{METHODS}

Bacterial strains. All bacteria were derivatives of E. coli K-12. Strain VC7 (thi-1 lys A23 rpsL109) was from our laboratory collection. Strain VC7001 is a derivative of VC7 carrying relA251::kan and spoT207::cat and is therefore unable to synthesize ppGpp (Rodionov \& Ishiguro, 1995). Strains VC56 (tbi-1 lys A23 rpsL109 gps $A$ zib-22:: Tn10) and VC58 (thi-1 lys $A 23$ rpsL109 gps $A$ zib-22: : $\operatorname{Tn} 10$ relA2) were constructed in this laboratory. The gps $A$ allele carried by these strains was derived from strain WN20, which was the gift of the late W. D. Nunn; this mutation resulted in an auxotrophic requirement for either glycerol 3-phosphate or glycerol. In our experiments, $0.05 \%$ glycerol was used to satisfy the nutritional requirement imposed by the $g p s A$ mutation.

Growth conditions. Bacteria were grown in $\mathrm{M} 9$ minimal medium containing required growth factors in a $37^{\circ} \mathrm{C}$ waterbath shaker as described previously (Ishiguro \& Ramey, 1976). The only exceptions were experiments involving radiolabelling with ${ }^{32} \mathrm{P}_{\mathrm{i}}$, which were carried out in Bell's (1974) modified M56LP low-phosphate medium. Glucose at $0.2 \%$ was used as the carbon source in all experiments except the one described in Fig. 2, in which case the carbon source was $0.4 \%$ glycerol (Rodionov et al., 1995). Strain VC7001 was grown in M9 medium containing $0 \cdot 1 \%$ Casamino acids (Difco). Culture turbidity was determined with a Beckman DU-64 spectrophotometer at $420 \mathrm{~nm}$.

Antibiotic treatment. The general methods for antibiotic treatment have been described previously (Kusser \& Ishiguro, 1985; Rodionov et al., 1995). Unless indicated otherwise, antibiotics were used at concentrations equal to about 10 times their minimum inhibitory concentrations (MICs). The MICs for the agents used in this study were $15 \mu \mathrm{g} \mathrm{ml}^{-1}$ for cerulenin, $5 \mu \mathrm{g}$ $\mathrm{ml}^{-1}$ for ampicillin, $6 \mu \mathrm{g} \mathrm{m} l^{-1}$ for cephaloridine, $0 \cdot 2 \mu \mathrm{g} \mathrm{ml}^{-1}$ for imipenem, $10 \mu \mathrm{g} \mathrm{ml}^{-1}$ for cefsulodin, and $15 \mu \mathrm{g} \mathrm{m} \mathrm{m}^{-1}$ for phosphonomycin. The inhibitory effect of cerulenin was reversed by supplementing the growth medium with a mixture of potassium oleate and potassium palmitate $\left(100 \mu \mathrm{g} \mathrm{ml}^{-1}\right.$ of each, final concentration) as described by Rodionov et al. (1995).

Assay of peptidoglycan synthesis. Bactetia were grown for two doublings in M9-glucose minimal medium to a density of $2 \times 10^{8}$ cells $\mathrm{ml}^{-1}$. meso-2,6-Diamino $\left[2,6-{ }^{3} \mathrm{H}\right]$ pimelic acid $\left(\left[{ }^{3} \mathrm{H}\right]\right.$ DAP; $\left.10 \mu \mathrm{Ci} \mu \mathrm{g}^{-1}\right)$ was added to a final concentration of $0.2 \mu \mathrm{g}$ $\mathrm{ml}^{-1}$, and incubation was continued for an additional $45 \mathrm{~min}$. Peptidoglycan synthesis was then assayed by measuring the incorporation of $\left[{ }^{3} \mathrm{H}\right] \mathrm{DAP}$ into cold trichloroacetic acid insoluble fractions as described by Ishiguro \& Ramey (1976).

Assay of phospholipid synthesis. Bacteria were grown for two doublings in M56LP low-phosphate medium to a density of $2 \times 10^{8}$ cells $\mathrm{ml}^{-1} \cdot{ }^{32} \mathrm{P}_{\mathrm{i}}\left(5 \mu \mathrm{Ci} \mathrm{m} l^{-1} ; 185 \mathrm{kBq} \mathrm{ml}^{-1}\right)$ was added, and the culture was incubated for an additional $45 \mathrm{~min}$ before incorporation of ${ }^{32} \mathrm{P}$ into the phospholipid fraction was measured. Phospholipids were extracted as described by Bligh \& Dyer (1959). The amounts of radioactivity in $200 \mu$ l aliquots 
of the chloroform fractions were quantified by liquid scintillation counting.

Quantification of ppGpp. The ppGpp fraction in cold formic acid extracts of ${ }^{32}$ P-labelled bacteria was quantified after separation by thin-layer chromatography on polyethyleneimine cellulose $\mathrm{F}$ plates developed in $1.5 \mathrm{M} \mathrm{KH}_{2} \mathrm{PO}_{4}$ as described by Rodionov \& Ishiguro (1995).

Assays for lysis. Antibiotic-induced lysis was routinely determined by measuring $\mathrm{OD}_{420}$. In addition, all experiments described were repeated using viable cell counts as a measure of lysis as described by Rodionov \& Ishiguro (1995). In one experiment, bacteria were prelabelled with $\left[{ }^{3} \mathrm{H}\right] \mathrm{DAP}$ and bacteriolysis was then determined by assaying the solubilization of radiolabelled peptidoglycan; this procedure has been described by Kusser \& Ishiguro (1986).

Liquid scintillation counting. Radioactive samples were counted in Ready Flow III liquid scintillation cocktail (Beckman) with a Beckman LS 8100 liquid scintillaion counter.

Materials. All antibiotics were purchased from Sigma except for imipenem and norfloxacin, which were obtained from Merck, Sharp \& Dohme. ${ }^{32} \mathrm{P}_{\mathrm{i}}$ (carrier-free, $10 \mathrm{mCi} \mathrm{ml}^{-1} ; 370 \mathrm{MBq} \mathrm{mi}^{-1}$ ) was obtained from Amersham. meso-2,6-Diamino[2,6- $\left.{ }^{3} \mathrm{H}\right] \mathrm{pi}-$ melic acid $\left(30 \mathrm{Ci} \mathrm{mmol}{ }^{-1} ; 1 \cdot 1 \mathrm{GBq} \mathrm{mmol}^{-1}\right)$ was purchased from American Radiolabeled Chemicals.

\section{RESULTS}

\section{Dependence of peptidoglycan synthesis on phospholipid synthesis during growth}

Fig. 1 shows the effects of different concentrations of cerulenin on growth, phospholipid synthesis and peptidoglycan synthesis in strain VC7. As expected, cerulenin inhibited growth (Fig. 1a) and phospholipid synthesis (Fig. 1b). However, cerulenin treatment also resulted in the inhibition of peptidoglycan synthesis (Fig. 1c). In all cases, the degrees of inhibition exhibited a direct dependence on the concentration of cerulenin employed.
The inhibition of peptidoglycan synthesis was considered significant because cerulenin was not a general inhibitor of macromolecular synthesis. For example, cerulenin did not inhibit either protein or DNA synthesis over the time course of these experiments when used at a concentration as high as $100 \mu \mathrm{g} \mathrm{ml} \mathrm{m}^{-1}$, i.e. 6.5 times the MIC. RNA synthesis was inhibited by $20 \%$ in the presence of $100 \mu \mathrm{g}$ cerulenin $\mathrm{ml}^{-1}$ but only after $40 \mathrm{~min}$ of treatment, and lower concentrations had no inhibitory effects. These results are in general agreement with those of Goldberg et al. (1973).

In additional experiments, peptidoglycan synthesis was determined in glycerol-limited cultures of the $g p s A$ mutant strains, VC56 and VC58. The gps $A$ gene encodes the biosynthetic $s n$-glycerol-3-phosphate dehydrogenase, and these strains were therefore dependent on an exogenous supply of glycerol (or glycerol 3-phosphate) for growth. Furthermore, phospholipid synthesis was arrested in these strains when the supply of glycerol was exhausted. In both cases, glycerol deprivation also resulted in the inhibition of peptidoglycan synthesis (data not shown). Collectively, the results of the experiments described above indicate that peptidoglycan synthesis in growing bacteria was dependent on concomitant phospholipid synthesis.

\section{Induction of $\beta$-lactam tolerance by cerulenin treatment of growing bacteria}

The effect of cerulenin treatment on the susceptibility of strain VC7 to ampicillin-induced bacteriolysis was tested. As shown in Fig. 2, lysis was initiated within 40 min when VC7 growing in glycerol-minimal medium was treated with ampicillin at $50 \mu \mathrm{g} \mathrm{ml}^{-1}$. The addition of cerulenin at $50 \mu \mathrm{g} \mathrm{ml}^{-1}$ at the same time as ampicillin resulted in the development of lysis tolerance. Furthermore, the combination of cerulenin and ampicillin inhibited growth
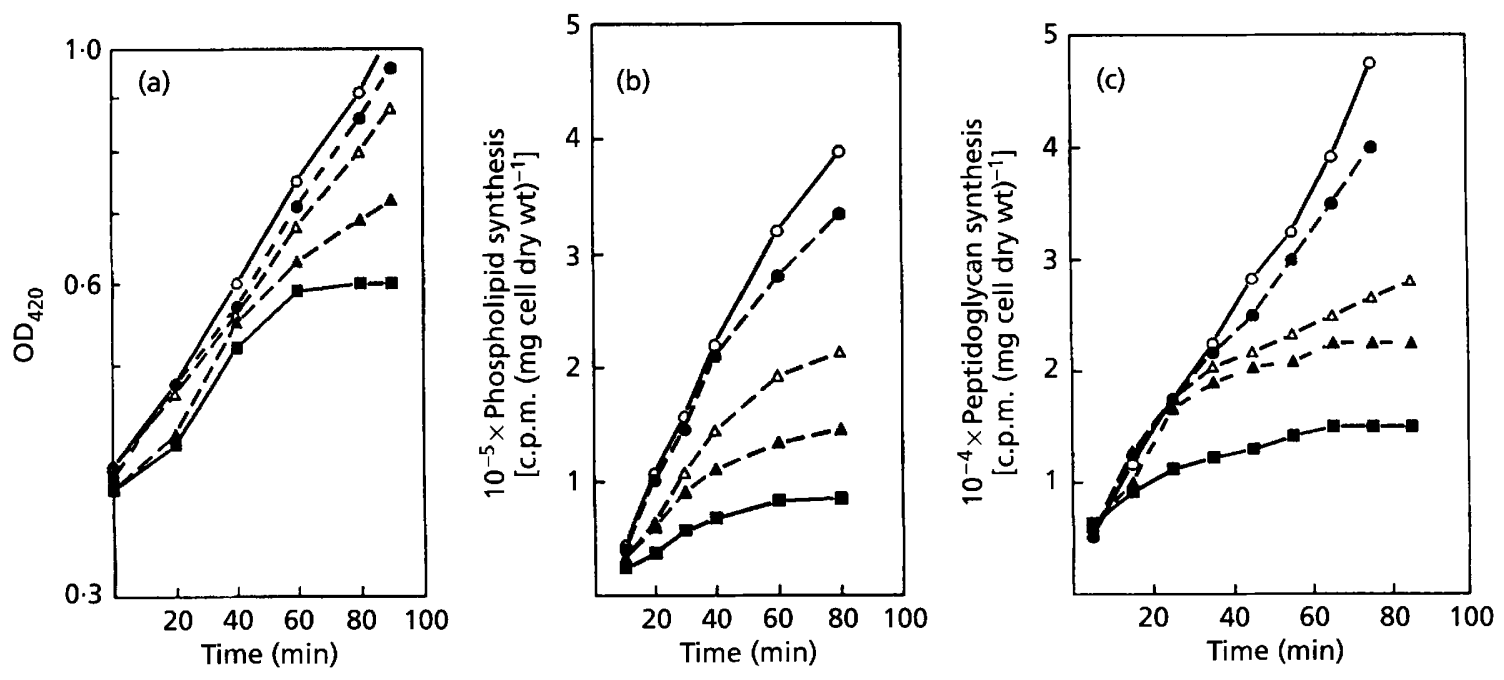

Fig. 1. Effect of cerulenin on growth (a), phospholipid synthesis (b), and peptidoglycan synthesis (c) in strain VC7. At 0 $\mathrm{min}$, cerulenin was added at $0(0), 12 \cdot 5(\bullet), 25(\triangle), 50(\Delta)$ and $100(\square) \mu \mathrm{g} \mathrm{ml}^{-1}$. 


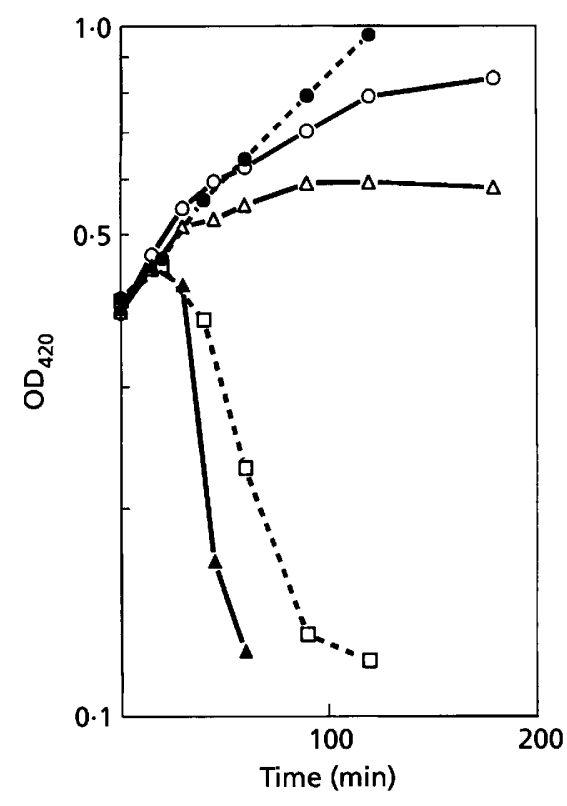

Fig. 2. Inhibitory effect of cerulenin on the ampicillin-induced lysis of strain VC7. At 0 min, portions of an exponential-phase culture growing in glycerol-minimal medium were treated with cerulenin (O), ampicillin ( $\boldsymbol{\Delta})$, a combination of cerulenin and ampicillin $(\triangle)$, and a combination of cerulenin and ampicillin along with a mixture of oleate and palmitate ( $\square$ ). An untreated control (Q) is shown for comparison.

sooner than cerulenin treatment alone, suggesting that cerulenin was not interfering with the interaction of ampicillin and its PBP targets. Finally, the addition of a mixture of oleate and palmitate not only reversed the growth-inhibitory activity of cerulenin but it also reversed the penicillin tolerance caused by cerulenin treatment. The same results were obtained when penicillin tolerance in this experiment was determined by viable cell counts rather than optical density measurements. Furthermore, in experiments using bacteria which were prelabelled with $\left[{ }^{3} \mathrm{H}\right] \mathrm{DAP}$, treatment with either cerulenin alone or cerulenin combined with ampicillin failed to cause measurable solubilization of the radiolabelled peptidoglycan. Therefore, these experiments collectively indicate that cerulenin treatment results in development of tolerance to ampicillin-induced lysis. Finally, it should be noted that cerulenin also induced tolerance to lysis by benzylpenicillin, imipenem, cefsulodin, cephaloridine and phosphonomycin.

\section{Penicillin tolerance was caused by inhibition of phospholipid synthesis}

Fig. 3 shows that glycerol deprivation of the $g p s A$ mutant, strain VC58, also resulted in ampicillin tolerance. Therefore, although cerulenin is an inhibitor of fatty acid synthesis, it is clear that its ability to cause penicillin tolerance was based on the inhibition of phospholipid synthesis resulting from fatty acid deprivation.

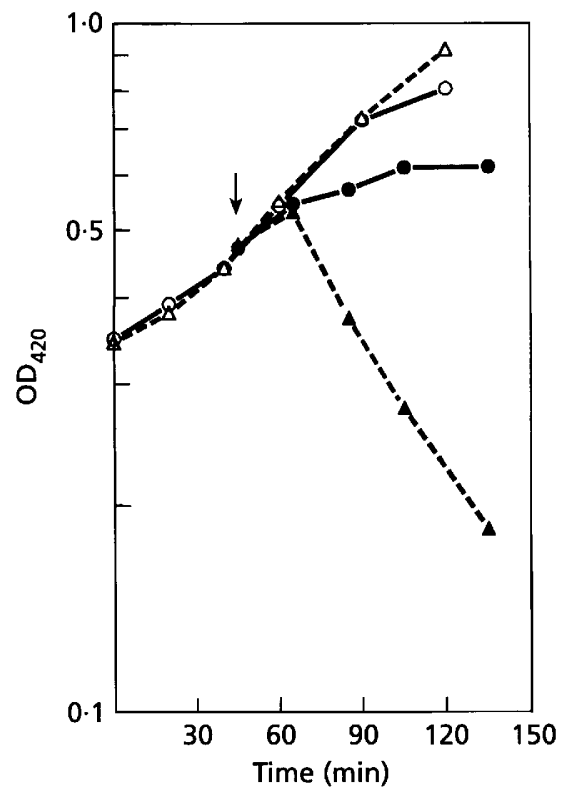

Fig. 3. Inhibitory effect of glycerol deprivation on ampicillininduced lysis of strain VC58 (gpsA). An exponential-phase culture of VC58 was deprived of glycerol beginning at 0 min. A portion of the original culture which was not glycerol-deprived is shown for comparison $(\triangle)$. At $\mathbf{4 5} \mathrm{min}$ (arrow), the glyceroldeprived culture was divided into three parts. One part was not treated further $(O)$. The other two parts were treated with ampicillin $\left(50 \mu \mathrm{g} \mathrm{ml}^{-1}\right)$ with $(\Delta)$ and without (ब) $0.05 \%$ glycerol.

The possibility that the observed penicillin tolerance was due simply to the inhibition of growth caused by cerulenin treatment or glycerol deprivation was considered. The experiments described in Fig. 4 make this unlikely, Treatment of strain VC7 with either chloramphenicol $\left(100 \mu \mathrm{g} \mathrm{ml}^{-1}\right.$; Fig. 4a) or norfloxacin $\left(10 \mu \mathrm{g} \mathrm{ml}^{-1}\right.$; Fig. 4b) resulted in almost immediate cessation of growth. In both cases, ampicillin still caused lysis in spite of the inhibition of growth. In fact, lysis induction by ampicillin was initiated earlier in the presence of chloramphenicol or norfloxacin; the basis for this is not known. The same results were obtained at concentrations closer to the MICs for these agents, e.g. $10 \mu \mathrm{g} \mathrm{ml}^{-1}$ for chloramphenicol and $1 \mu \mathrm{g} \mathrm{ml}^{-1}$ for norfloxacin.

\section{Penicillin tolerance was not due to ppGpp accumulation}

As noted above, Seyfzadeh et al. (1993) showed that fatty acid deprivation induced the accumulation of ppGpp. They further showed that ppGpp did not accumulate during glycerol deprivation of a $g p s A$ mutant and the effect was therefore not due to inhibition of phospholipid synthesis. We have already shown (Fig. 3) that glycerol deprivation of the $g p s A$ mutant, strain VC58, resulted in ampicillin tolerance. Therefore, the ampicillin tolerance observed in our studies was not due to ppGpp accumulation induced by fatty acid deprivation resulting 

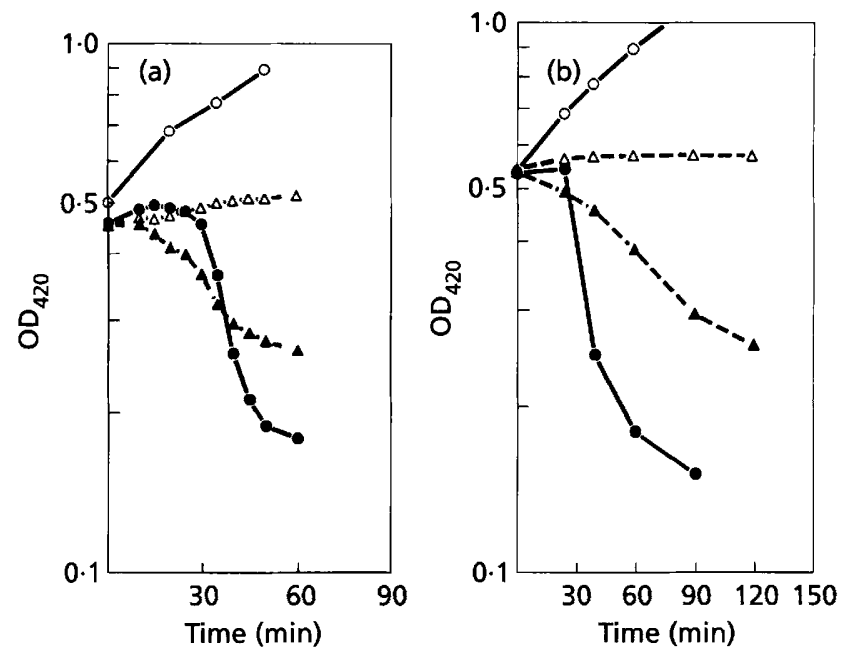

Fig. 4. Effects of ribosome and DNA gyrase inhibitors on ampicillin-induced lysis of strain VC7. Exponential-phase cultures were divided into four parts. In (a), one subculture received no further treatment $(0)$. The other subcultures were treated with $100 \mu \mathrm{g} \mathrm{ml}^{-1}$ chloramphenicol $(\triangle)$, ampicillin (O), and a combination of ampicillin and chloramphenicol ( $\boldsymbol{A})$. In (b), one subculture served as an untreated control (O). The other subcultures were treated with norfloxacin $(\triangle)$, ampicillin (O), and a combination of norfloxacin and ampicillin ( $\mathbf{\Delta})$. The concentrations of the agents used were $100 \mu \mathrm{g} \mathrm{ml}^{-1}$ for chloramphenicol, $50 \mu \mathrm{g} \mathrm{ml}^{-1}$ for ampicillin, and $10 \mu \mathrm{g} \mathrm{ml}^{-1}$ for norfloxacin.

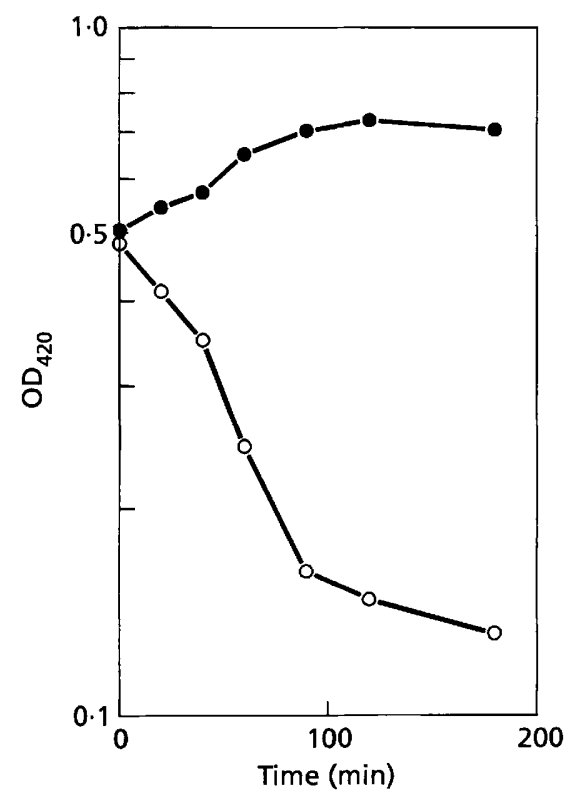

Fig. 5. Effect of cerulenin treatment on ampicillin-induced lysis of strain VC7001 (relA spoT). Portions of an exponential phase culture were treated with ampicillin in the presence $(0)$ and absence $(O)$ of $50 \mu \mathrm{g}$ cerulenin $\mathrm{ml}^{-1}$.

from the cerulenin treatment. To further establish this point, two additional experiments were performed. In the first of these experiments, the ppGpp levels during cerulenin treatment were quantified. The peak accumulation was determined to be $450 \mathrm{pmol}$ ( $\mathrm{mg}$ cell dry weight $)^{-1}$. In comparison, the basal level in normal exponential-phase bacteria was 40 pmol ppGpp (mg cell dry weight $)^{-1}$. Therefore, cerulenin treatment caused over a 10-fold accumulation of ppGpp but, significantly, this was still far less than the minimum amount required to establish ampicillin tolerance, which was previously determined to be $870 \mathrm{pmol}$ ( $\mathrm{mg}$ cell dry weight) ${ }^{-1}$ (Rodionov \& Ishiguro, 1995). In the second experiment, we constructed a $\operatorname{rel} A$ spoT derivative of $\mathrm{VC} 7$, strain VC7001. This strain was truly ppGpp-deficient; i.e. ppGpp was undetectable in amino-acid-deprived bacteria and in cerulenin-treated bacteria. Fig. 5 shows that cerulenin treatment of strain VC7001 resulted in ampicillin tolerance. Together, these results indicate that the observed ampicillin tolerance was directly related to the inhibition of phospholipid synthesis and not to ppGpp accumulation.

\section{DISCUSSION}

We have shown here that peptidoglycan metabolism was coupled to phospholipid synthesis during growth of $E$. coli. This phenomenon is therefore not a unique aspect of amino-acid-deprived bacteria. The observed dependence of peptidoglycan synthesis on phospholipid synthesis may represent an important means of coordinating cell envelope synthesis in growing bacteria. On the other hand, membrane protein synthesis may not be similarly coupled to phospholipid synthesis since the protein to phospholipid ratios in both the inner and outer membranes were found to increase by about $60 \%$ when phospholipid synthesis was inhibited in E. coli (McIntyre \& Bell, 1975). Nevertheless, bacteria still generally maintain a constant protein to phospholipid ratio during steady growth, but how this is accomplished is not known (Cronan \& Rock, 1987).

Leduc et al. (1982) previously showed that E. coli cells pretreated with cerulenin for $30 \mathrm{~min}$ were tolerant to penicillin-induced lysis. They concluded that lysis exhibited a dependence on fatty acids but did not elaborate on the nature of this dependence. In this regard, it is widely accepted that nongrowing or slow-growing bacteria are penicillin-tolerant, and it was possible that the observed penicillin tolerance was simply due to the inhibition of growth brought about by fatty acid deprivation. For example, Tuomanen et al. (1986) have demonstrated in experiments involving chemostat-grown cultures of $E$. coli that the rate of killing by $\beta$-lactam antibiotics is directly related to the growth rate of the bacteria. However, several observations suggest that the penicillin tolerance observed in the experiments reported here was not due to the inhibition of growth resulting from either cerulenin treatment or glycerol deprivation. First, lysis of untreated control cultures in our experiments was initiated before there were any detectable changes in the growth rates of the treated cultures (Figs 2 and 3). Second, agents which caused abrupt inhibition of growth, e.g. chloramphenicol and norfloxacin (Fig. 4), did not cause penicillin tolerance, indicating that in- 
hibition of growth by itself was not sufficient to prevent penicillin-induced lysis under our experimental conditions. Third, we have previously demonstrated that the penicillin tolerance of amino-acid-deprived E. coli is based on the inhibition of phospholipid synthesis, and the dependence of peptidoglycan metabolism on phospholipid synthesis (Rodionov et al., 1995; Rodionov \& Ishiguro, 1995). We therefore conclude that the penicillin tolerance reported here in growing bacteria was a direct consequence of the inhibition of phospholipid synthesis. It should be noted that we have also unequivocally ruled out the possibility that the inhibitory effect of cerulenin treatment on penicillin-induced lysis was mediated by ppGpp. This is relevant in view of the demonstration by Seyfzadeh et al. (1993) that fatty acid deprivation results in ppGpp accumulation.

Our previous studies with amino-acid-deprived $E$. coli have suggested that the membrane-bound enzymic reactions in peptidoglycan metabolism are dependent on phospholipid synthesis (Ishiguro, 1983; Rodionov et al., 1995). However, the mechanistic basis for this is unknown. A model for peptidoglycan synthesis involving a membrane-bound multienzyme complex composed of both PBPs and peptidoglycan hydrolases has been proposed by Höltje (1993), and evidence for the existence of such a multienzyme complex has been presented (Romeis \& Höltje, 1994). It is possible that some aspect of either the assembly or the function of the putative multienzyme complex may be dependent on phospholipid synthesis.

The pattern of cell envelope synthesis during the cell cycle of $E$. coli has been the subject of numerous reports (reviewed by Cronan \& Rock, 1987; Cooper, 1991). Although they are not all in agreement, some provide circumstantial evidence suggesting a link between membrane phospholipid synthesis and peptidoglycan metabolism. For example, several reports indicate that the rate of phospholipid synthesis increases abruptly at the onset of septum formation and remains high throughout the process of cell division (Carty \& Ingram, 1981; Hakenbeck \& Messer, 1977a; Pierucci, 1979). An increase in the rate of peptidoglycan synthesis has also been shown to occur during this period (Hoffman et al., 1972). Furthermore, the activities of several peptidoglycan hydrolases undergo cell-cycle-dependent fluctuations (Beck \& Park, 1976; Hakenbeck \& Messer, 1977b; Mirelman et al., 1978). Gally et al. (1993) have also studied the synthesis of peptidoglycan and membrane during the cell division cycle of E. coli and Salmonella typhimurium, and it is important to note that they did not observe cell cycle fluctuations in peptidoglycan and phospholipid synthesis.

Gally et al. (1993) concluded that cell surface synthesis in E. coli and $S$. typhimurium is regulated primarily, and possibly solely, by mass increase, and they proposed that the peptidoglycan layer enlarges in response to the accumulation of cell mass. Furthermore, they suggested that the cell membrane grows passively in response to the enlargement of the peptidoglycan layer. Our conclusion is just the opposite, namely that peptidoglycan expansion is dependent on membrane phospholipid synthesis. These differences of opinion will need to be addressed in future studies.

\section{ACKNOWLEDGEMENTS}

This work was supported by a grant from the Natural Sciences and Engineering Research Council of Canada to E. E. I.; D.G.R. was the recipient of the Ray Hadfield Memorial Scholarship from the University of Victoria. We are grateful to Desiree Vanderwel for invaluable technical assistance in the early phases of this study.

\section{REFERENCES}

Beck, B. D. \& Park, J. T. (1976). Activity of three murein hydrolases during the cell division cycle of Escherichia coli $\mathrm{K}-12$ as measured in toluene-treated cells. J Bacterial 126, 1250-1260.

Bell, R. M. (1974). Mutants of Escherichia coli defective in membrane phospholipid synthesis: macromolecular synthesis in an $s$ glycerol 3-phosphate acyltransferase $K_{\mathrm{m}}$ mutant. I Bacteriol 117, $1065-1076$

Bligh, E. G. \& Dyer, W. J. (1959). A rapid method of total lipid extraction and purification. Can J Biochem Pbysiol 379, 911-917.

Carty, C. E. \& Ingram, L. O. (1981). Lipid synthesis during the Escherichia coli cell cycle. J Bacteriol 145, 472-478.

Cashel, M. \& Rudd, K. E. (1987). The stringent response, In Escherichia coli and Salmonella typhimurium: Cellular and Molecular Biology, pp. 1410-1438. Edited by F. C. Neidhardt, J. L. Ingraham, K. Brooks Low, B. Magasanik, M. Schaechter \& H. E. Umbarger. Washington, DC: American Society for Microbiology.

Cooper, S. (1991). Svnthesis of the cell surface during the division cycle of rod-shaped, Gram-negative bacteria. Microbiol Rev 55, 649-674.

Cronan, J. E., Jr \& Rock, C. O. (1987). Biosynthesis of membrane lipids, In Escherichia coli and Salmonella typhimurium: Cellular and Molecular Biology, pp. 474-497. Edited by F. C. Neidhardt, J. L. Ingraham, K. Brooks Low, B. Magasanik, M. Schaechter \& H. E. Umbarger. Washington, DC: American Society for Microbiology.

Gally, D., Bray, K. \& Cooper, S. (1993). Synthesis of peptidoglycan and membrane during the division cycle of rod-shaped, Gramnegative bacteria. J Bacteriol 175, 3121-3130.

Goldberg, I., Walker, J. R. \& Bloch, K. (1973). Inhibition of lipid synthesis in Eschericbia coli cells by the antibiotic cerulenin. Antimicrob Agents Chemother 3, 549-554.

Hakenbeck, R. \& Messer, W. (1977a). Oscillations in the synthesis of cell wall components in synchronized cultures of Escherichia coli. J Bacteriol 129, 1234-1238.

Hakenbeck, R. \& Messer, W. (1977b). Acitivity of murein hydrolases in synchronized cultures of Escherichia coli. J Bacteriol $129,1239-1244$.

Heath, R. J., Jackowski, S. \& Rock, C. O. (1994). Guanosine tetraphosphate inhibition of fatty acid and phospholipid synthesis in Escherichia coli is relieved by overexpression of glycerol-3phosphate acyltransferase ( $p l s B)$. J Biol Chem 269, 26584-26590.

Hernandes, V.J. \& Bremer, H. (1991). Escherichia coli ppGpp synthetase II activity requires spoT. J Biol Chem 266, 5991-5999.

Hoffman, B., Messer, W. \& Schwarz, U. (1972). Regulation of polar cap formation in the life cycle of Escherichia coli. I Supramol Struct 1 , 29-32.

Höltje, J. -V. (1993). 'Three for one' - a simple growth mechanism that guarantees a precise copy of the thin, rod-shaped murein sacculus of Escherichia coli. In Bacterial Growth and Lysis. Metabolism 
of the Bacterial Sacculus, pp. 419-426. Edited by M. A. de Pedro, J.-V. Höltje \& W. Löffelhardt. New York \& London: Plenum Press. Höltje, J.-V. (1995). From growth to autolysis: the murein hydrolases in Eschericbia coli. Arch Microbiol 164, 243-254.

Höltje, J.-V. \& Tuomanen, E. I. (1991). The murein hydrolases of Escherichia coli: properties, functions and impact on the course of infections in vivo. J Gen Microbiol 137, 441-454.

Ishiguro, E. E. (1983). Mechanism of stringent control of peptidoglycan synthesis in Escherichia coli. In The Target of Penicillin, pp. 631-636. Edited by R. Hakenbeck, J.-V. Höltje \& H. Labischinski. Berlin: Walter de Gruyter.

Ishiguro, E. E. \& Ramey, W. D. (1976). Stringent control of peptidoglycan biosynthesis in Escherichia coli K-12. J Bacteriol 127, 1119-1126.

Kusser, W. \& Ishiguro, E. E. (1985). Involvement of the $\operatorname{rel} A$ gene in the autolysis of Eschericbia coli induced by inhibitors of peptidoglycan biosynthesis. J Bacteriol 164, 861-865.

Kusser, W. \& Ishiguro, E. E. (1986). Lysis of nongrowing Eschericbia coli by combinations of $\beta$-lactam antibiotics and inihibitors of ribosome function. Antimicrob Agents Chemother 29, 451-455.

Leduc, M., Kasra, R. \& van Heijenoort, J. (1982). Induction and control of the autolytic system of Escherichia coli. J Bacteriol 152, 26-34.

McIntyre, T. M. \& Bell, R. M. (1975). Mutants of Escherichia coli defective in membrane phospholipid synthesis. Effect of cessation of net phospholipid synthesis on cytoplasmic and outer membranes. J Biol Cbem 250, 9053-9059.

Mirelman, D., Yashouv-Gan, Y., Nuchamovitz, Y., Rozenhak, S. \& Ron, E. Z. (1978). Murein biosynthesis during a synchronous cell cycle of Escherichia coli B. J Bacteriol 134, 458-461.
Pierucci, O. (1979). Phospholipid synthesis during the cell division cycle of Eschericbia coli. J Bacteriol 138, 453-460.

Rodionov, D. G. \& Ishiguro, E. E. (1995). Direct correlation between overpoduction of guanosine $3^{\prime}, 5^{\prime}$-bispyrophosphate (ppGpp) and penicillin tolerance in Escherichia coli. J Bacteriol 177, 4224-4229.

Rodionov, D. G., Pisabarro, A. G., De Pedro, M. A., Kusser, W. \& Ishiguro, E. E. (1995). $\beta$-Lactam-induced bacteriolysis of aminoacid-deprived Escherichia coli is dependent on phospholipid synthesis. J Bacteriol 177, 992-997.

Romeis, T. \& Höltje, J.-V. (1994). Specific interaction of penicillinbinding proteins 3 and $7 / 8$ with soluble lytic transglycosylase in Escherichia coli. J Biol Chem 269, 21603-21607.

Seyfzadeh, M., Keener, J. \& Nomura, M. (1993). $\mathrm{Mg}^{2+}$-dependent accumulation of guanosine tetraphosphate in response to fatty acid starvation. Proc Natl Acad Sci US A 90, 11004 11008.

Sokawa, Y., Nakao, E. \& Kaziro, Y. (1968). On the nature of the control by RC gene in E. coli: amino acid-dependent control of lipid synthesis. Biochem Biophys Res Commun 33, 108-112.

Tuomanen, E., Cozens, R., Tosch, W., Zak, O. \& Tomasz, A. (1986). The rate of killing of Escherichia coli by $\beta$-lactam antibiotics is strictly proportional to the rate of bacterial growth. J Gen Microbiol 132, 1297-1304.

Xiao, H., Kalman, M., Ikehara, K., Zemel, S., Glaser, G. \& Cashel, M. (1991). Residual guanosine $3^{\prime}, 5^{\prime}$-bispyrophosphate synthetic activity of $\operatorname{rel} A$ null mutants can be eliminated by spoT null mutations. J Biol Chem 266, 5980-5990.

Received 9 April 1996; revised 24 June 1996; accepted 4 July 1996. 